\title{
Pengaruh Perilaku Konsumsi Islam terhadap Pengendalian Diri pada Mahasiswa Penerima Beasiswa X
}

\author{
Andum Laras Kintani *, Arif Rijal Anshori \\ Prodi Hukum Ekonomi Syariah, Fakultas Syariah, Universitas Islam \\ Bandung, Indonesia. \\ *andumlaraskin@gmail.com, arijalanshori89@gmail.com
}

\begin{abstract}
Consumption in Islam is defined as the fulfillment of something in the form of goods or services according to needs. In managing finances, students should be able to use it according to what is needed. The purpose of this study was to determine the effect of Islamic consumption behavior and self-control of students receiving the Bawaku scholarship at Unisba for the 2019/2020 academic year. The research method used is quantitative with the type of field data. Sources of data using primary and secondary data in the form of a questionnaire. Data analysis used descriptive statistics and simple linear regression which was processed using SPSS software. The sample in this study amounted to 67 Unisba students who received my scholarships for the 2019/2020 academic year. The result of this research is that the variable of Islamic consumption behavior on self-control is $1.645<1.997$, it means tcount $<$ ttable $(1.645<1.997)$ with a significance level of $0.105>0.05$. From this, it can be concluded that $\mathrm{H} 0$ is accepted and $\mathrm{H} 1$ is rejected, which means that there is no positive and insignificant effect between the variables of Islamic consumption behavior on self-control. In the Islamic consumption variable (X) it can be seen that the total average value is 39.79 with a percentage of $82.90 \%$ and is in good criteria. While the self-control variable has an average value of 21.57 with a percentage of $67.40 \%$, which means that it is in the moderate or sufficient criteria.
\end{abstract}

Keywords: Islamic Consumption Behavior, Self Control.

Abstrak. Konsumsi dalam Islam di definisikan sebagai pemenuhan atas sesuatu baik berupa barang ataupun jasa sesuai dengan kebutuhan. Dalam mengelola keuangan seharusnya mahasiswa dapat menggunakan sesuai dengan apa yang dibutuhkan. Tujuan penelitian ini adalah untuk mengetahui pengaruh perilaku konsumsi Islam dan pengendalian diri mahasiswa penerima beasiswa bawaku di unisba tahun ajaran 2019/2020. Metode peneltiain yang digunakan ialah kuantitatif dengan jenis data lapangan. Sumber data menggunakan data primer dan sekunder berupa kuesioner. Analisis data menggunakan statistik deskriptif dan regresi linier sederhana yang diolah menggunakan software SPSS. Sampel dalam penelitian ini berjumlah 67 mahasiswa unisba penerima beasiswa bawaku tahun ajaran 2019/2020. Hasil dari penelitian ini bahwa pada variable perilaku konsumsi Islam terhadap pengendalian diri adalah $1,645<1,997$ hal tersebut berarti $\mathrm{t}_{\text {hitung }}<\mathrm{t}_{\text {tabel }}(1,645<1,997)$ dengan tingkat signifikasi 0,105>0,05. Dari hal tersebut dapat disimpulkan bahwa berarti Ho diterima dan Hi ditolak yang berarti tidak terdapat pengaruh positif dan tidak signifikan antara variabel perilaku konsumsi Islam terhadap pengendalian diri. Pada variabel konsumsi Islam (X) dapat diketahui bahwa jumlah total nilai rata-rata sebesar 39,79 dengan persentase $82.90 \%$ dan berada pada kriteria baik. Sedangkan pada variabel pengendalian diri memiliki nilai rata-rata sebesar 21,57 dengan persentase $67,40 \%$ yang artinya berada pada kriteria sedang atau cukup.

Kata Kunci: Perilaku Konsumsi Islam, Pengendalian Diri. 


\section{A. Pendahuluan}

Menurut M. Abdul Mannan, "consumtion is to demand as production is to supply" yang artinya konsumsi merupakan suatu permintaan, sedangkan produksi merupakan penyediaan.(1) Ada 5 prinsip dalam konsumsi islam, antara lain prinsip keadilan, prinsip kebersihan, prinsip kesederhanaan, prinsip kemurahan hati dan prinsip moralitas.(2) Sedangkan menurut Yusuf alQardhawi terdapat tiga prinsip yaitu menjauhi sifat kikir, kesederhanaan, membelanjakan harta dalam kebaikan dan tidak melakukan kemubaziran.(3) Pendapat para tokoh ini, pada intinya adalah satu yaitu bersumber pada Al-Qur'an dan Sunnah. Sebagaimana firman Allah dalam alQur'an, sebagai berikut:

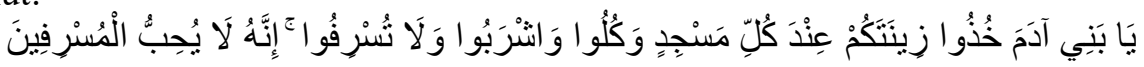

"Wahai anak cucu Adam! Pakailah pakaianmu yang bagus pada setiap (memasuki) masjid, makan dan minumlah tetapi jangan berlebihan. Sesungguhnya, Allah tidak menyukai orang yang berlebih-lebihan." (QS. Al-A'raf [7]: 31) (4)

Ayat di atas maksudnya adalah hendaknya setiap mengerjakan sembahyang atau ibadahibadah yang lain menggunakan pakaian yang menutupi aurat dan tidak berlebih-lebihan. Allah ingin manusia membelanjakan hartanya secara wajar dan proporsional.

Menurut pandangan Islam, konsumsi Islam didasarkan pada kebutuhan sehingga tidak berlebih-lebihan. Pada dasarnya seluruh yang ada didunia ini halal dan baik untuk dikonsumsi, namun dalam Islam berkonsumsi memiliki aturan tertentu, tidak hanya sekedar menghabiskan nilai guna dari suatu barang namun ada aturan bagaimana etika dalam berkonsumsi. (5)

Menurut Gufron dan Rini dikutip dari Dewi Kumalasari dan Yohanes, menyebutkan bahwa pengendalian diri diartikan sebagai kemampuan untuk menyusun, membimbing, mengatur, dan mengarahkan bentuk perilaku yang membawa ke arah konsekuensi positif.(6)

Menurut penelitian Heni yang dikutip dari Regina, Lydia dan Cicilia antara self-control dengan perilaku konsumtif terdapat hubungan negatif. Adanya tanda negatif berarti semakin tinggi self-control dalam diri seseorang maka akan disertai dengan penururan tingkat perilaku konsumtif. Begitu pula sebaliknya, semakin turun self-control dalam diri seseorang, akan disertai dengan meningkatnya perilaku konsumtif. (7) Sehingga semakin tinggi kontrol diri semakin intens pengendalian terhadap tingkah laku dalam berkonsumsi agar tidak konsumtif.

Hal yang dapat dilakukan agar tidak berperilaku konsumtif dalam berkosumsi adalah dengan mendahulukan kebutuhan dari pada keinginan karena selain tidak konsumtif, juga dapat menghemat pengeluaran dan yang paling penting adalah kesadaran dari diri masing-masing individu.

Subjek yang paling mudah dalam mengikuti perubahan arus globalisasi yang identik dengan hal-hal modern adalah mahasiswa. Mahasiswa banyak yang mengikuti tren fashion, belanja online, mengikuti perkembangan gadget bahkan berlibur di tempat-tempat yang terkenal. (8)

Beasiswa merupakan bantuan yang diberikan sebagai bentuk penghargaan berupa sejumlah uang kepada mahasiswa, pelajar ataupun individu yang akan melanjutkan pendidikan.(Arief Soma Darmawan, 2012). Tujuan adanya beasiswa adalah untuk membantu meringankan biaya pendidikan, sebagaimana dalam Peraturan Pemerintah No. 48 Tahun 2008 Pasal 5 tentang Pendanaan Pendidikan.(10)

Adanya beasiswa di setiap perguruan tinggi sudah menjadi fasilitas, baik perguruan tinggi negeri maupun swasta. Salah satu perguruan tinggi swasta yang memiliki fasilitas beasiswa didalamnya adalah Universitas Islam Bandung. Namun, berdasarkan hasil wawancara kepada 10 orang responden, 5 diantaranya menjawab bahwa alokasi dana yang didapatkan dari beasiswa bawaku tidak digunakan sepenuhnya untuk kepentingan perkuliahan. Hal tersebut dikhawatirkan berpengaruh terhadap perilaku konsumtif atau konsumsi yang berlebihan, karena salah satu indikatornya adalah prinsip kesederhanaan.(2). Sehingga perlu dilakukannya analisis mengenai pengendalian diri mahasiswa, salah satunya dengan mengetahui pengaruh perilaku konsumsi. Berdasarkan uraian dari latar belakang diatas maka, perumusan masalah dalam penelitian ini adalah sebagai berikut:

1. Bagaimana perilaku konsumsi Islam dan pengendalian diri mahasiswa penerima beasiswa bawaku di Universitas Islam Bandung? 
2. Bagaimana pengaruh perilaku konsumsi islam terhadap pengendalian diri pada mahasiswa penerima beasiswa bawaku (Studi Pada Mahasiswa Universitas Islam Bandung Tahun 2019/2020)?

Selanjutnya, tujuan dalam penelitian ini diuraikan dalam pokok-pokok sebagai berikut:

1. Untuk mengetahui perilaku konsumsi Islam dan pengendalian diri mahasiswa penerima beasiswa bawaku di Universitas Islam Bandung.

2. Untuk mengetahui pengaruh perilaku konsumsi islam terhadap pengendalian diri pada mahasiswa penerima beasiswa bawaku (Studi Pada Mahasiswa Universitas Islam Bandung Tahun 2019/2020).

\section{B. Metodologi Penelitian}

Penelitian ini adalah penelitian kuantitatif dengan pendekatan survei yang digunakan dengan cara menyebarkan kuesioner kepada mahasiswa penerima beasiswa bawaku tahun ajaran 2019/2020 di unisba. Populasi yang dipilih dalam penelitian ini adalah mahasiswa UNISBA penerima beasiswa bawaku tahun ajaran 2019/2020 yang berjumlah 67 mahasiswa.

Dengan jenis data yang digunakan adalah data lapangan. Data lapangan penelitian ini diperoleh dengan cara menyebarkan kuesioner. Sumber data menggunakan data Primer dan Sekunder, data primer diperoleh dari hasil kuesioner yang disebarkan kepada mahasiswa penerima beasiswa bawaku tahun ajaran 2019/2020 di unisba. Sedangkan data sekunder diperoleh dari buku, jurnal, tesis, serta website unisba. Pada penelitian ini menggunakan dua jenis teknik pengumpulan data, yang pertama berupa kuesioner dan yang kedua adalah studi pustaka. Teknik analisis data berupa uji validitas, uji reliabilitas, uji korelasi, uji determinan, uji hipotesis, dan analisis regresi linier sederhana. Hipotesis dalam penelitian ini adalah sebagai berikut:

1. $\mathrm{H}_{0}=$ Diduga tidak terdapat pengaruh antara perilaku konsumsi Islam terhadap pengendalian diri pada mahasiswa penerima beasiswa bawaku.

2. $\mathrm{H}_{1}=$ Diduga terdapat pengaruh antara perilaku konsumsi Islam terhadap pengendalian diri pada mahasiswa penerima beasiswa bawaku.

\section{Hasil Penelitian dan Pembahasan \\ Deskripsi Data Responden}

Data responden dalam penelitian ini sesuai dengan yang dibutuhkan yaitu 67 orang mahasiswa penerima beasiswa bawaku di unisba tahun ajaran 2019/2020. Karakteristik berdasarkan angkatan didominasi oleh angkatan 2017 sebanyak 32 orang dengan persentase 47,7\%. Karakteristik berdasarkan fakultas didominasi oleh fakultas syariah sebanyak 17 orang dengan persentase $25,4 \%$. Karakteristik berdasrkan usia didominasi antara usia 20-23 tahun sebanyak 52 orang dengan persentase $77,6 \%$. Karakteristik berdasarkan uang jajan perbulan berkisar antara 500.000-1.000.000 sebanyak 29 orang dengan persentase 43,3\%.

\section{Analisis Deskriptif}

Hasil rata-rata dari setiap variable yang didapat, akan dibandingkan dengan kriteria yang telah peneliti tentukan dari hasil penyebaran kuesioner. Dengan berdasarkan nilai terendah 1 (satu) dan nilai tertinggi 4 (empat), sebagai berikut:

1. Variabel $\mathrm{X}$ terdapat 12 pernyataan

Nilai terendah: Skor minimum x Jumlah pernyataan $=1 \times 12=12$

Nilai tertinggi: Skor maksimum x Jumlah pernyataan $=4 \times 12=48$

Jarak interval: (Nilai Tertinggi - Nilai Terendah) $/$ Jumlah Kategori $=(48-12) / 5=7,2$

Berdasarkan hal tersebut, maka kriteria untuk melihat variabel konsumsi Islam (X) adalah: 
Tabel 1. Kriteria Konsumsi Islam

\begin{tabular}{|c|c|}
\hline Nilai & Frekuensi \\
\hline $12-19,2$ & Tidak Baik \\
\hline $19,2-26,4$ & Kurang Baik \\
\hline $26,4-33,6$ & Cukup \\
\hline $33,6-40,8$ & Baik \\
\hline $40,8-48$ & Sangat Baik \\
\hline
\end{tabular}

Sumber: Hasil olah data Penulis, 2021.

2. Variabel $\mathrm{Y}$ terdapat 8 pernyataan

Nilai terendah: Skor minimum x Jumlah pernyataan $=1 \times 8=8$

Nilai tertinggi: Skor maksimum x Jumlah pernyataan $=4 \times 8=32$

Jarak interval: (Nilai Tertinggi - Nilai Terendah) $/$ Jumlah Kategori $=(32-8) / 5=4,8$

Berdasarkan hal tersebut, maka kriteria untuk melihat variabel konsumsi Islam $(\mathrm{X})$ adalah:

Tabel 2. Kriteria Pengendalian Diri

\begin{tabular}{|c|c|}
\hline Nilai & Frekuensi \\
\hline $8-12,8$ & Sangat Rendah \\
\hline $12,8-17,6$ & Rendah \\
\hline $17,6-22,4$ & Sedang \\
\hline $22,4-27,2$ & Tinggi \\
\hline $27,2-31$ & Sangat Tinggi \\
\hline
\end{tabular}

Sumber: Hasil olah data Penulis, 2021.

Hasil analisis deskriptif dari jawaban responden pada variabel perilaku konsumsi Islam (X) diperoleh jumlah total nilai rata-rata sebesar sebesar 39,79 dengan persentase $82.90 \%$. Apabila dilihat dari nilai rata-rata, konsumsi Islam berada pada kriteria baik. Maka dapat disimpulkan bahwa mahasiswa penerima beasiswa bawaku di unisba angkatan 2019/2020 sudah memahami konsumsi Islam dengan baik. Sedangkan hasil analisis deskriptif dari jawaban responden pada variabel pengendalian diri $(\mathrm{Y})$ diperoleh jumlah total nilai rata-rata sebesar 21,57 dengan persentase $67,40 \%$. Apabila dilihat dari nilai rata-rata, pengendalian diri berada pada kriteria sedang atau cukup. Maka dapat disimpulkan bahwa mahasiswa penerima beasiswa bawaku di unisba angkatan 2019/2020 memiliki pengendalian diri yang cukup dalam berkonsumsi.

\section{Uji Kualitas Data}

\section{Uji Validitas}

Dibawah ini merupakan hasil dari setiap pernyataan pada uji validitas, sebahgai berikut: 
Tabel 3. Rekapitulasi Uji Validitas Variabel X

\begin{tabular}{|l|c|c|c|}
\hline \multicolumn{1}{|c|}{ No. } & $\mathbf{r}_{\text {hitung }}$ & $\mathbf{r}_{\text {tabel }}$ & Ket. \\
\hline 1. & 0.635 & 0.2404 & Valid \\
\hline 2. & 0.576 & 0.2404 & Valid \\
\hline 3. & 0.72 & 0.2404 & Valid \\
\hline 4. & 0.627 & 0.2404 & Valid \\
\hline 5. & 0.768 & 0.2404 & Valid \\
\hline 6. & 0.698 & 0.2404 & Valid \\
\hline 7. & 0.74 & 0.2404 & Valid \\
\hline 8. & 0.693 & 0.2404 & Valid \\
\hline 9. & 0.677 & 0.2404 & Valid \\
\hline 10. & 0.673 & 0.2404 & Valid \\
\hline 11. & 0.538 & 0.2404 & Valid \\
\hline 12. & 0.586 & 0.2404 & Valid \\
\hline
\end{tabular}

Sumber: Hasil Olah Data Penulis, 2021

Tabel 4. Rekapitulasi Uji Validitas Variabel Y

\begin{tabular}{|l|c|c|c|}
\hline No. & $\mathbf{r}_{\text {hitung }}$ & $\mathbf{r}_{\text {tabel }}$ & Ket. \\
\hline 1. & 0.818 & 0.2404 & Valid \\
\hline 2. & 0.895 & 0.2404 & Valid \\
\hline 3. & 0.864 & 0.2404 & Valid \\
\hline 4. & 0.895 & 0.2404 & Valid \\
\hline 5. & 0.745 & 0.2404 & Valid \\
\hline 6. & 0.795 & 0.2404 & Valid \\
\hline 7. & 0.491 & 0.2404 & Valid \\
\hline 8. & 0.787 & 0.2404 & Valid \\
\hline
\end{tabular}

Sumber: Hasil Olah Data Penulis, 2021

Berdasarkan hasil diatas dapat disimpulkan bahwa dapat diketahui bahwa seluruh kuesioner yang disebarkan dinyatakan valid dan memenuhi syarat $r_{\text {hitung }} \geq r_{\text {tabel. }}$. Nilai $r_{\text {tabel }}$ dapat diketahui dengan rumus $d f=n-2=67-2=65$. Hasil uji validitas pada variabel perilaku konsumsi Islam $(\mathrm{X})$ dan pengendalian diri $(\mathrm{Y})$ menunjukan hasil yang signifikan dengan $\mathbf{r}_{\text {hitung }}$ $>r_{\text {tabel }}$ sebesar 0,2404 dan nilai signifikasi dari kedua variabel $<0,05$. Maka dapat dinyatakan bahwa semua item pernyataan valid untuk digunakan dalam intrumen penelitian.

Uji Reliabilitas

Hasil olah data uji reliabilitas adalah sebagai berikut:

Tabel 5. Hasil Uji Reabilitas Variabel X

\begin{tabular}{|ll|}
\hline Reliability Statistics \\
\hline $\begin{array}{l}\text { Cronbach's } \\
\text { Alpha }\end{array}$ & N of Items \\
\hline 0.893 & 12 \\
\hline
\end{tabular}

Sumber: Hasil olah data dengan SPSS versi 26

Tabel 6. Hasil Uji Reabilitas Variabel X

\begin{tabular}{|l|l|}
\hline \multicolumn{2}{|l|}{ Reliability Statistics } \\
\hline $\begin{array}{l}\text { Cronbach's } \\
\text { Alpha }\end{array}$ \\
\hline 0.915 & N of Items \\
\hline
\end{tabular}

Sumber: Hasil olah data dengan SPSS versi 26 
Berdasarkan hasil diatas dapat disimpulkan bahwa uji reliabilitas pada variabel konsumsi Islam dan pengendalian diri, dapat diketahui bahwa nilai Cronbach's Alpha variabel $\geq 0,6$. Nilai dari masing-masing variabel $\geq 0,6$ karena Cronbach's Alpha variabel konsumsi Islam (X) sebesar 0,893 dan Cronbach's Alpha variabel pengendalian diri (Y) sebesar 0,915. Dapat disimpulkan bahwa seluruh pernyataan dari setiap variabel $\mathrm{X}$ dan $\mathrm{Y}$ telah memenuhi persyaratan reliabel dan dapat digunakan pada tahapan selanjutnya. (11)

\section{Uji Korelasi}

Hasil uji korelasi pada penelitian ini adalah sebagai berikut:

Tabel 7. Hasil Koefisien Regresi Sederhana

\begin{tabular}{|c|c|c|c|}
\hline \multicolumn{4}{|c|}{ Correlations } \\
\hline & & $\mathrm{KI}$ & PD \\
\hline \multirow[t]{2}{*}{$\mathrm{KI}$} & $\begin{array}{l}\text { Pearson } \\
\text { Correlation }\end{array}$ & 1 & 0.200 \\
\hline & $\begin{array}{l}\text { Sig. }(2- \\
\text { tailed) }\end{array}$ & & 0.105 \\
\hline \multirow{4}{*}{ PD } & $\mathrm{N}$ & 67 & 67 \\
\hline & $\begin{array}{l}\text { Pearson } \\
\text { Correlation }\end{array}$ & 0.200 & 1 \\
\hline & $\begin{array}{l}\text { Sig. }(2- \\
\text { tailed) }\end{array}$ & 0.105 & \\
\hline & $\mathrm{N}$ & 67 & 67 \\
\hline
\end{tabular}

Berdasarkan hasil diatas dapat disimpulkan bahwa uji korelasi memiliki nilai sebesar 0,200 yang berarti konsumsi Islam dan pengendalian diri memiliki korelasi yang kuat dan memiliki hubungan positif. semakin tinggi tingkat perilaku konsumsi Islam yang didapat akan semakin rendah pengendalian diri yang dilakukan, begitu pula sebaliknya. Pada hasil uji korelasi, didapatkan nilai siginifikasi sebesar 0,105 yang berarti $\mathrm{H}_{\mathrm{o}}$ diterima dan $\mathrm{H}_{\mathrm{i}}$ ditolak, artinya tidak terdapat korelasi antara konsumsi Islam terhadap pengendalian diri. (12)

\section{Analisis Regresi Linier Sederhana}

Hasil perhitungan koefisien regresi dilakukan menggunakan SPSS dan diperoleh hasil sebagai berikut:

Tabel 8. Analisis Regresi Linier Sederhana

\begin{tabular}{|c|c|c|c|c|c|c|}
\hline \multicolumn{7}{|c|}{ Coefficients $^{\mathrm{a}}$} \\
\hline \multirow[b]{2}{*}{ Mode } & \multicolumn{2}{|c|}{$\begin{array}{l}\text { Unstandardized } \\
\text { Coefficients }\end{array}$} & \multirow{2}{*}{\multicolumn{2}{|c|}{$\begin{array}{c}\text { Standardized } \\
\text { Coefficients } \\
\text { Beta }\end{array}$}} & \multirow[b]{2}{*}{$\mathrm{t}$} & \multirow[b]{2}{*}{ Sig. } \\
\hline & B & $\begin{array}{r}\mathrm{St} \\
\mathrm{Err}\end{array}$ & & & & \\
\hline 1 & (Constant) & 13.108 & 5.180 & & 2.530 & 0.014 \\
\hline & $\begin{array}{l}\text { Konsumsi } \\
\text { Islam }\end{array}$ & 0.213 & 0.129 & 0.200 & 1.645 & 0.105 \\
\hline
\end{tabular}

Sumber: Hasil olah data dengan SPSS versi 26

Pada tabel 1 maka diperoleh persamaan sebagai berikut:

1. Nilai konstanta (Y): Apablila perilaku konsumsi Islam (X) memiliki nilai 0 (nol) maka pengendalian diri (Y) sebesar 13,108.

2. Nilai koefisien (X) Apablila perilaku konsumsi Islam (X) memiliki nilai 1 satuan maka Uji T pengendalian diri (Y) sebesar 0,213. (13)

Dalam menentukan $t_{\text {tabel }}$ dapat dihitung dengan rumus $(n-k-1=67-1-1=65)$. Berdasarkan hal tersebut didapatkan hasil $t_{\text {tabel }}$ sebesar 1,997. Dapat diketahui bahwa pada variable perilaku konsumsi Islam adalah 1,645 $<1,997$ maka hasil $\mathrm{t}_{\text {hitung }}<\mathrm{t}_{\text {tabel }}(1,645<1,997)$ dengan tingkat 
signifikasi 0,105 > 0,05. Dari hal tersebut dapat disimpulkan bahwa berarti Ho ditolak dan Hi diterima yang berarti tidak terdapat pengaruh positif dan tidak signifikan antara variabel perilaku konsumsi Islam terhadap pengendalian diri pada mahasiswa penerima beasiswa bawaku di unisba tahun ajaran 2019/2020.

\section{Uji Determinan}

Hasil uji koefisien determinan dilakukan menggunakan SPSS dan diperoleh hasil sebagai berikut:

Tabel 9. Hasil Koefisien Determinan

\begin{tabular}{|c|c|c|c|c|}
\hline \multicolumn{5}{|c|}{ Model Summary } \\
\hline Model & $\mathrm{R}$ & R Square & $\begin{array}{l}\text { Adjusted R } \\
\text { Square }\end{array}$ & $\begin{array}{l}\text { Std. Error of } \\
\text { the Estimate }\end{array}$ \\
\hline 1 & $.200^{a}$ & 0.040 & 0.025 & 5.038 \\
\hline
\end{tabular}

Sumber: Hasil olah data dengan SPSS versi 26

Berdasarkan hasil uji koefisien determinan, dapat diketahui besarnya koefisien determinan (R Square) sebesar 0,040 atau 0,4\%. Berdasarkan hal tersebut dapat disimpulkan bahwa perilaku konsumsi Islam atau variable $\mathrm{X}$ dapat atau mampu untuk menjelaskan pengendalian diri atau variable $\mathrm{Y}$ sebesar $0,4 \%$. Sedangkan nilai sisa yang didapat sebesar $0,996 \%(100 \%-0,4 \%)$ merupakan variable lain yang tidak termasuk atau tidak dijelaskan pada penelitian ini.

\section{Kesimpulan}

Berdasarkan pembahasan dalam penelitian ini, peneliti menyimpulkan beberapa hasil penelitian sebagai berikut:

1. Perilaku mahasiswa penerima beasiswa bawaku di Universitas Islam Bandung tahun ajaran 2019/2020 terkait dengan konsumsi Islam. Pada variable konsumsi Islam (X) dapat diketahui bahwa jumlah total nilai rata-rata (mean) sebesar 39,79 dengan persentase $82.90 \%$. nilai rata-rata (mean) berada pada kriteria baik. Maka dapat disimpulkan bahwa mahasiswa penerima beasiswa bawaku di unisba angkatan 2019/2020 sudah memahami konsumsi Islam dengan baik. Pengendalian diri yang dilakukan oleh mahasiswa penerima beasiswa bawaku di Universitas Islam Bandung tahun ajaran 2019.2020 berada pada kriteria sedang atau cukup. Dengan total nilai ratarata (mean) sebesar 21,57 dengan persentase 67,40\%. Maka dapat disimpulkan bahwa mahasiswa penerima beasiswa bawaku di unisba angkatan 2019/2020 memiliki pengendalian diri yang cukup dalam berkonsumsi.

2. Hipotesis yang menyatakan bahwa perilaku konsumsi Islam berpengaruh terhadap pengendalian diri tidak terbukti. Hal tersebut dibuktikan dari hasil analisis data yang menyatakan bahwa pada variable perilaku konsumsi Islam terhadap pengendalian diri adalah 1,645 < 1,997 hal tersebut berarti thitung < ttabel $(1,645<1,997)$ dengan tingkat signifikasi 0,105 > 0,05. Dari hal tersebut dapat disimpulkan bahwa berarti Ho diterima dan Hi ditolak yang berarti tidak terdapat pengaruh positif dan tidak signifikan antara variabel perilaku konsumsi Islam terhadap pengendalian

\section{Acknowledge}

Penulis mengucapkan banyak terima kasih kepada dosen pembimbing satu dan dosen pembimbing dua yang telah membimbing penulis dalam menyusun penelitian ini hingga selesai. 


\section{Daftar Pustaka}

[1] Kelik Wardiono KD dan SR. Problema globalisasi: perspektif sosiologi hukum, ekonomi, dan agama. Muhammadiyah Univ Press. 2008;46.

[2] Zuliana. Prinsip Konsumsi Dalam Islam Berbasis Nilai Material Dan Spiritual (Analisis Konsep M. Abdul Mannan dan Aktualisasinya dengan Prinsip Konsumsi di Indonesia). Universitas Islam Negeri Walisongo Semarang; 2015.

[3] Kurniati. Teori Perilaku Konsumen Perspektif Ekonomi Ekonomi Islam. J Ekon Syariah Indones. 2016;49.

[4] Departemen Agama RI. Al-Qur'an dan Terjemahannya. Bandung: J-ART; 2004. 154 p.

[5] Jenita. Konsep Konsumsi Dan Perilaku Konsumsi Islam. J Ekon dan Bisnis. 2017;2.

[6] Dewi Kumalasari\&Yohanes Hadi Soesilo. Pengaruh Literasi Keuangan, Modernitas Individu, Uang Saku Dan Kontrol Diri Terhadap Perilaku Konsumtif Mahasiswa Prodi S1 Pendidikan Ekonomi Angkatan Tahun 2016 Fakultas Ekonomi Universitas Negeri Malang. J Pendidik Ekon. 2019;62.

[7] Regina C.M.Chita, Lydia David CP. Hubungan Antara Self-Control Dengan Perilaku Konsumtif Online Shopping Produk Fashion Pada Mahasiswa Fakultas Kedokteran Universitas Sam Ratulangi Angkatan 2011. J e-Biomedik. 2015;5.

[8] Fitri Yuyun Aisah. Pengaruh Pengendalian Diri Dan Literasi Keuangan Terhadap Perilaku Konsumtif Mahasiswa Pendidikan Bisnis Angkatan 2017 Fakultas Ekonomi Universitas Negeri Medan. 2020.

[9] Arief Soma Darmawan. Pemilihan Beasiswa Bagi Mahasiswa STMIK WIDYA PRATAMA Dengan Metode Profile Matching. J Ilm ICTech. 2012;1.

[10] PP RI N 4. Peraturan Pemerintah Republik Indonesia Nomor 48 Tahun 2008 Tentang Pendanaan Pendidikan [Internet]. 2008. p. 11. Available from: https://jdih.kemenkeu.go.id/

[11] Suhar Janti. Analisis Validitas Dan Reliabilitas Dengan Skala Likert Terhadap Pengembangan Si/Ti Dalam Penentuan Pengambilan Keputusan Penerapan Strategic Planning Pada Industri Garmen. Semin Nas Apl Sains Teknol. 2014;2.

[12] Wandy Zulkarnaen, Iis Dewi RW. Pengaruh Motivasi Kerja Terhadap Prestasi Kerja Karyawan PT. Alva Karya Perkasa Bandung. J Manajemen, Ekon dan Akunt. 2017;1:15.

[13] I Made Yuliara. Modul Regresi Linier Sederhana. J Mat Dan Ilmu Pengetah Alam. 2016;5. 